\title{
SISTEM PENDUKUNG KEPUTUSAN KLINIS MANAJEMEN NEONATAL BERBASIS ALGORITMA MTBS
}

\author{
R. N. Karimah ${ }^{1}$, R.r. Lia Chairina ${ }^{2}$, A.P. Wicaksono ${ }^{3}$ \\ Program Studi Rekam Medik, Jurusan Kesehatan, Politeknik Negeri Jember \\ ${ }^{1}$ rinda nurulepolije.ac.id \\ radenrorolia@yahoo.com \\ 3andriperman4@gmail.com
}

\begin{abstract}
The neonatal period is an important period in life. Infant Mortality Rate (IMR) is the number of infant deaths in the first 28 days of life (neonatal) per 1000 live births (PERMENKES No 53, 2014). IMR in Indonesia is still high compared to other ASEAN countries, data in 2016 shows that IMR reaches 25.5, it's meaning that there are around 25.5 deaths per 1,000 babies born (BPS, 2016). Poor neonatal management clinically will cause abnormalities, and can even lead to lifelong disability, and death, while administratively can cause legal problems. Neonatal management requires complete clinical data support, relevance, accurate and timeliness aspects. This research is a mixed method research with action research approach and prototype method in the development of Clinical Decision Support System (CDSS). This study produced CDSS based on Integrated Childhood Illness Management (IMCI) algorithm for neonatal service management in primary health care center. The results of testing system using black-box technique is accordance with the requirements and obtained a valid overall result. DSS IMCI can be integrated with Electronic Health Record (EHR) so can occur for appropriate clinical decision making.
\end{abstract}

Keywords - CDSS, IMCI, Neonatal Management.

\section{Pendahuluan}

Penelitian menunjukkan bahwa lebih dari $50 \%$ kematian bayi terjadi pada periode neonatal yaitu dalam bulan pertama kehidupan. Neonatal adalah bayi usia nol sampai dengan 28 hari. [1,2] Hasil riset Badan Pusat Statistik (BPS) menunjukkan bahwa angka kematian bayi sudah menurun sejak tahun 2012 hingga 2016, tetapi data di tahun 2016 menunjukkan AKB masih tinggi yaitu mencapai 25,5 artinya ada sekitar 25,5 kematian setiap 1000 bayi lahir. [3] Penanganan bayi baru lahir yang kurang baik akan menyebabkan kelainan bahkan dapat mengakibatkan cacat seumur hidup dan kematian.

Tindakan pencegahan merupakan hal terbaik yang harus dilakukan dalam penanganan neonatal karena periode neonatal merupakan periode yang paling kritis dalam fase pertumbuhan dan perkembangan bayi. Diagnosis berperan penting dalam perawatan medis, diperlukan pengambilan keputusan yang tepat dalam melakukan diagnosis dan tindakan. Hal tersebut perlu diketahui dengan baik oleh tenaga kesehatan khususnya bidan, yang selalu memberikan pelayanan kesehatan bagi ibu dan bayi. Penyebab tertinggi mortalitas neonatus bedasarkan data statistik WHO adalah prematuritas, komplikasi pada saat persalinan (asfiksia neonatorum), dan sepsis [4]. Bayi baru lahir memerlukan asuhan yang segera, cepat, tepat, dan aman. Proses persalinan pada umumnya terfokus pada ibu, tetapi penatalaksanaan persalinan baru dikatakan berhasil jika ibu dan bayinya dalam kondisi sehat optimal. Fasilitas kesehatan primer merupakan sarana pelayanan kesehatan tingkat pertama yang berperan sebagai gerbang pelayanan kesehatan tingkat lanjut. Adanya kejadian penculikan dan perdagangan bayi yang termasuk kriteria perdagangan orang (traficking in person) juga harus menjadi perhatian khusus dan menambah 
urgensi kebutuhan kelengkapan data pada pelayanan bayi baru lahir [5]. Penerapan teknologi informasi diperlukan sebagai solusi untuk mendukung kelengkapan data dan pendukung keputusan klinis dalam pelayanan persalinan [6]

Kementrian Kesehatan RI menerbitkan pedoman teknis pelayanan kesehatan dasar pada neonatal berupa Manajemen Terpadu Balita Sakit (MTBS). MTBS ditujukan untuk menurunkan angka kematian bayi dan balita yang diperankan oleh tenaga kesehatan di pusat pelayanan kesehatan baik primer maupun sekunder yang memberi pelayanan kesehatan neonatal [7]. Implementasi MTBS membutuhkan pengklasifikasian secara sistematis dan penatalaksanaan yang khusus, dimana tenaga kesehatan harus mampu menguasai algoritma pengklasifikasian tersebut di level pelayanan kesehatan primer. Kendala yang sering dijumpai dilapangan adalah banyak dari tenaga kesehatan memiliki pengetahuan yang terbatas terkait algoritma MTBS.

Penerapan teknologi informasi berupa Sistem Pendukung Keputusan Klinis (SPKK) diharapkan dapat meningkatkan efisiensi dan keamanan pelayanan kesehatan. Penggunaan SPKK berbasis algoritma MTBS di fasilitas pelayanan kesehatan primer diharapkan mampu berperan sebagai alat bantu dalam pengklasifikasian dan penatalaksanaan kasus pada pelayanan neonatal. SPKK dapat dipadukan dengan Rekam Kesehatan Elektronik (RKE) sehingga dapat terjadi integrasi untuk pengambilan keputusan klinis. Hal tersebut berdampak pada terwujudnya peningkatan kualitas pelayanan kesehatan.

\section{TinJAUAN PUSTAKa}

Manajemen Terpadu Balita Sakit (MTBS) adalah suatu manajemen melalui pendekatan terintegrasi/terpadu dalam tatalaksana balita sakit yang datang di pelayanan kesehatan, baik mengenai beberapa klasifikasi penyakit, status gizi, status imunisasi maupun penanganan balita sakit tersebut dan konseling yang diberikan. Materi MTBS terdiri dari langkah penilaian, klasifikasi penyakit, identifikasi tindakan, pengobatan, konseling, perawatan di rumah dan kapan kembali untuk tindak lanjut. Sasaran MTBS adalah anak umur 0-5 tahun dan dibagi menjadi dua kelompok sasaran yaitu kelompok usia 1 hari sampai 2 bulan dan kelompok usia 2 bulan sampai 5 tahun. Kegiatan MTBS merupakan upaya yang ditujukan untuk menurunkan angka kesakitan dan kematian sekaligus meningkatkan kualitas pelayanan kesehatan di pelayanan kesehatan primer. World Health Organization (WHO) telah mengakui bahwa pendekatan MTBS sangat cocok diterapkan negaranegara berkembang dalam upaya menurunkan kematian, kesakitan, dan kecacatan pada bayi dan balita. MTBS telah digunakan di lebih dari 100 negara dan terbukti dapat [8]:

1. Menurunkan angka kematian balita,

2. Memperbaiki status gizi,

3. Meningkatkan pemanfaatan pelayanan kesehatan, 4.Memperbaiki kinerja petugas kesehatan,

5.Memperbaiki kualitas pelayanan dengan biaya lebih murah.

Sistem Pendukung Keputusan (SPK) bisa diartikan sebagai sautu aplikasi dari pengolahan data dan menghasilkan suatu analisa keputusan yang dapat digunakan untuk proses pengambilan keputusan. Salah satu penggunaan SPK yang populer dan sangat membantu kehidupan adalah dalam bidang kesehatan atau biasa disebut dengan Clinical Decision Support System (CDSS) atau Sistem Penunjang Keputusan Klilnis (SPKK).CDSS membangun aplikasi prediksi kesehatan [9]. Sistem Pendukung Keputusan Klinis memiliki pontensial yang besar dalam peningkatan kualitas kesehatan dan efektivitas perawatan kesehatan yang lebih baik. Manfaat Sistem Pendukung Keputusan klinis (SPKK) adalah sistem pendukung keputusan klinis yang biasanya dirancang untuk mengintegrasikan pengetahuan dasar medis, data pasien dan mesin inferensi untuk menghasilkan saran dari penyakit khusus. Empat fungsi utama SPKK elektronik sebagai berikut:

1. Administrasi: mendukung coding data klinis, dokumentasi, otorisasi prosedur, dan referal;

2. Mengelola kompleksitas klinis: merawat pasien (penelitian dan protokol terapi; pelacakan order, follow up, pencegahan dan perawatan);

3. Kontrol biaya: monitoring pesanan obat; menghindari duplikasi atau pemeriksaan yang tidak perlu;

4. Pendukung keputusan dalam mendiagnosis, perawatan dan mempromosikan praktek terbaik, panduan khusus dan manajemen.

Manfaat SPKK dalam praktek ada tiga kategori yaitu: 
1. Meningkatkan keselamatan pasien: mengurangi medical error, meningkatkan ketepatan pengobatan dan pemesanan obat;

2. Meningkatkan kualitas pelayanan, mempersingkat waktu perawatan, peningkatan clinical pathway dan guideline, penggunaan evidence base yang up-to-date, meningkatkan dokumentasi klinis dan kepuasan pasien;

3. Meningkatkan efisiensi yaitu mengurangi biaya karena urutan pemrosesan lebih cepat, menghindari pemeriksaan berulang, memberikan obat generik berkualitas baik yang murah [11] [12].

Prototyping model adalah proses pengembangan perangkat lunak yang diawali dengan pengumpulan kebutuhan dari sistem, yang dilanjutkan dengan pembuatan prototipe dan evaluasi dari pengguna. Tahapan-tahapan Model Prototyping [3] [14]:

a. Pengumpulan Kebutuhan: pelanggan dan pengembang bersamasama mendefinisikan format seluruh perangkat lunak, mengidentifikasikan semua kebutuhan, dan garis besar sistem yang akan dibuat.

b. Membangun Prototyping: membangun prototyping dengan membuat perancangan sementara yang berfokus pada penyajian kepada pelanggan (misalnya dengan membuat input dan format output).

c. Menggunakan Sistem Evaluasi ini dilakukan oleh pelanggan apakah prototyping yang sudah dibangun sudah sesuai dengan keinginann pelanggan.

d. Mengkodekan Sistem : Dalam tahap ini prototyping yang sudah di sepakati diterjemahkan ke dalam bahasa pemrograman yang sesuai.

e. Menguji Sistem Setelah sistem sudah menjadi suatu perangkat lunak yang siap pakai, harus dites dahulu sebelum digunakan. Pengujian ini dilakukan dengan White Box, Black Box, Basis Path, pengujian arsitektur dan lain-lain.

f. Evaluasi Sistem: Pelanggan mengevaluasi apakah sistem yang sudah jadi sudah sesuai dengan yang diharapkan.

g. Menggunakan sistem : Perangkat lunak yang telah diuji dan diterima pelanggan siap untuk digunakan.

Action research atau penelitian tindakan merupakan salah satu bentuk rancangan penelitian, dalam penelitian tindakan peneliti mendeskripsikan, menginterpretasi dan menjelaskan suatu situasi sosial pada waktu yang bersamaan dengan melakukan perubahan atau intervensi dengan tujuan perbaikan atau partisipasi. Tujuan action research memiliki dua karakteristik spesifik yaitu [15]:

a.Proses action reseach merupakan sebuah siklus yang didalamnya mencakup kegiatan intervensi, oleh karena itu dinamakan action research.

b. Tingkat keterlibatan subjek dalam penelitian sangat besar, mulai dari pemilihan subjek sebagai informan hingga intervensi.

Bentuk tahapan action research yang paling sederhana, setidaknya terdapat 4 tahap dalam penelitian. Keempat tahapan tersebut adalah [16]:

1. Diagnosing action

2. Planning action

3. Taking action

4. Evaluating action

\section{Metode PEnelitian}

\section{a. Rancangan Penelitian}

Penelitian ini menggunakan metode action research dan model prototipe dalam perancangan sistem yang dibangun. Action research merupakan salah satu bentuk rancangan penelitian, dimana peneliti dapat mendeskripsikan, menginterpretasi dan menjelaskan suatu situasi sosial pada waktu yang bersamaan dengan melakukan perubahan atau intervensi dengan tujuan perbaikan atau partisipasi. Adapun tahapan penelitian berdasarkan metode action research adalah sebagai berikut [15] :



Gambar 3.1 Tahap Penelitian

Tahapan penelitian meliputi:

1. Tahap diagnosis

Melakukan identifikasi masalah-masalah pokok yang ada terkait manajemen pelayanan neonatal di fasilitas pelayanan kesehatan guna menjadi dasar untuk perancangan aplikasi. Pada tahap ini peneliti mengidentifikasi kebutuhan tenaga kesehatan baik dokter maupun bidan di fasilitas pelayanan 
kesehatan dalam melaksanakan manajemen neonatal, dilakukan dengan melakukan wawancara mendalam dan observasi.

\section{Tahap Perencanaan Aksi}

Peneliti dan responden (dokter dan bidan) bersama-sama memahami pokok masalah yang ada terkait pelaksanaan pelayanan kesehatan neonatal, kemudian dilanjutkan dengan menyusun rencana tindakan yang tepat untuk menyelesaikan masalah yang ada berdasarkan algoritma MTBS. Pada tahap ini perancangan aplikasi mulai memasuki tahapan perancangan sistem dengan menggunakan model perancangan prototype. Peneliti bersama responden membuat sketsa awal perencanaan algoritma SPKK dan menentukan isi yang akan ditampilkan di aplikasi.

3. Tahap Pelaksanaan Aksi

Tahap ini peneliti mengimplementasikan rencana tindakan ke perancangan antarmuka SPKK, database, mesin inferensi sesuai dengan kebutuhan sistem.

4. Tahap Evaluasi

Uji coba prototype SPKK pelayanan neonatal dilakukan di fasilitas pelayanan kesehatan yang melayani manajemen neonatal. Tahap ini ditujukan untuk mengetahui kemungkinan kesulitan penggunaan aplikasi SPKK dalam pelayanan manajemen neonatal berbasis algoritma MTBS.

\section{b. Lokasi Penelitian}

Penelitian ini akan dilakukan di klinik Sakinah Kaliurang, yaitu salah satu klinik pratama di wilayah kerja puskesmas Sumbersari Kabupaten Jember yang menyelenggarakan manajemen pelayanan neonatal berbasis algoritma MTBS dengan bidan jejaring yang tersebar wilayahnya. Perancangan dan pembuatan aplikasi dilakukan di laboratorium IT jurusan Kesehatan Politeknik Negeri Jember.

\section{c. Unit Analisis}

Unit analisis pada penelitian ini adalah seluruh dokter dan bidan yang bertugas melaksanakan manajemen pelayanan neonatal di fasilitas pelayanan primer dalam hal ini khususnya klinisi di klinik Sakinah Kaliurang dan bidan jejaringnya. Terdapat 2 orang dokter dan 4 orang bidan.

\section{d. Model Perancangan Sistem}

Model yang akan digunakan untuk perancangan sistem SPKK pada penelitian ini adalah prototyping model, yaitu model perancangan yang cepat dan pengujian terhadap model kerja (prototipe) dari aplikasi baru melalui proses interaksi dan berulang-ulang yang biasa digunakan ahli sistem informasi dan ahli bisnis [10]. Dengan metode prototyping ini pengembang dan pengguna (user) dapat saling berinteraksi selama proses pembuatan sistem [14]. Model prototype pada penelitian ini terdiri dari langkah sebagai berikut:

\section{Pengumpulan kebutuhan}

Peneliti dan responden (user) bersama-sama mendefinisikan format dan kebutuhan keseluruhan perangkat lunak. Pada penelitian ini dilakukan wawancara dan observasi untuk mengidentifikasikan semua kebutuhan, dan garis besar sistem yang akan dibuat.

\section{Membangun prototyping}

Membangun prototyping dengan membuat perancangan sementara yang berpusat pada penyajian kepada user (misalnya dengan membuat input dan contoh output-nya) berdasarkan algoritma MTBS. Pada tahap ini peneliti membuat desain sistem dan perangkat lunak dengan memperhatikan kebutuhan yang telah diketahui dari tahap sebelumnya. Tahap ini meliputi pembuatan (diagram alir) flowchart, Data Flow Diagram (DFD), Entity Relationship Diagram $(E R D)$ dan pembuatan database.

3. Evaluasi protoptyping

Evaluasi ini dilakukan oleh responden apakah prototyping yang sudah dibangun sudah sesuai dengan keinginan responden sebagai user. Jika sudah sesuai maka langkah keempat akan diambil. Jika tidak, maka prototyping diperbaiki dengan mengulang langkah 1, 2, dan 3 .

4. Mengkodekan sistem

Tahap ini prototyping yang sudah disepakati dilakukan koding dengan diterjemahkan ke dalam bahasa pemrograman.

5. Menguji system

Pada tahap ini dilakukan uji dari segi lojik dan fungsionalitas program untuk meneliti dan meminimalisir terjadinya error.

6. Evaluasi Sistem

User mengevaluasi apakah sistem yang sudah jadi sudah sesuai dengan yang diharapkan. Jika sudah, maka langkah ketujuh dilakukan, jika belum maka mengulangi langkah 4 dan

7. Menggunakan sistem 
Perangkat lunak SPKK manajemen neonatal yang telah diuji dan diterima user siap untuk digunakan

\section{e. Teknik Pengumpulan dan Analisis Data}

Teknik pengumpulan data pada penelitian ini adalah wawancara dan observasi serta diskusi. Teknik analisis data yang digunakan dalam penelitian action research ini adalah deskriptif kualitatif, yaitu dilakukan analisis data secara kualitatif dan disajikan secara deskriptif.

Uji validitas merupakan suatu cara untuk menentukan suatu keabsahan data yang diperoleh. Dalam hal ini, untuk meningkatkan validitas data yang diperoleh, peneliti menggunakan triangulasi data. Triangulasi data yang digunakan yaitu:

1. Triangulasi waktu

2. Triangulasi sumber

3. Triangulasi metode

\section{HaSil Dan PEMbahasaN}

\section{Tahap diagnosis}

Tahap diagnosis dilakukan dengan memasuki tahap awal model prototipe yaitu identifikasi kebutuhan. Tahap ini dilakukan identifikasi kebutuhan Identifikasi kebutuhan yang dimaksud adalah kebutuhan terhadap prototype SPKK manajemen neonatal di FKTP. Pengambilan data melalui kegiatan observasi, wawancara dan diskusi dengan klinisi pelaksana pelayanan klinis neonatal di FKTP dalam hal ini khususnya klinisi di klinik Sakinah Kaliurang dan bidan jejaringnya. Terdapat 6 orang responden pada penelitian ini yaitu 2 orang bidan satu atap dan 2 bidan jejaring serta 2 orang dokter. Hasil identifikasi kebutuhan diperoleh kebutuhan responden terkait dukungan saat pelaksanaan pelayanan klinis bayi baru lahir berupa kewaspadaan umum (universal precaution) saat penilaian awal sebelum bayi lahir dan segera setelah bayi baru lahir. Dukungan yang dibutuhkan berupa alur tindakan terorganisir sebagai implementasi MTBS (Manajemen Terpadu Balita Sakit) dan kebutuhan keseragaman formulir terkait instrumen penangkapan kelengkapan data serta terkait legalitas dari pendokumentasian yang dilakukan termasuk pengeluaran surat keterangan kelahiran. Hasil kesimpulan wawancara dan diskusi tersebut kemudian peneliti kombinasikan dengan referensi terkait regulasi yang berlaku dari DEPKES yaitu Peraturan Menteri Kesehatan Republik Indonesia Nomor 53 Tahun 2014 Tentang Pelayanan Kesehatan Neonatal Esensial pasal 4 ayat 2 tentang pelayanan neonatal esensial 0 (nol) sampai 6 (enam) jam meliputi :

a. Menjaga bayi tetap hangat;

b. Inisiasi menyusu dini;

c. Pemotongan dan perawatan tali pusat;

d. Pemberian suntikan vitamin $\mathrm{k} 1$;

e. Pemberian salep mata antibiotik;

f. Pemberian imunisasi hepatitis b0;

g. Pemeriksaan fisik bayi baru lahir;

h. Pemantauan tanda bahaya;

i. Penanganan asfiksia bayi baru lahir;

j. Pemberian tanda identitas diri;

k. Merujuk kasus yang tidak dapat ditangani dalam kondisi stabil, tepat waktu ke fasilitas pelayanan kesehatan yang lebih mampu.

Hal tersebut juga sesuai dengan regulasi yang terdapat pada panduan pelayanan kesehatan neonatal essensial, sehingga disimpulkan kebutuhan data yang diperlukan terkait pengembangan sistem pendukung kelengkapan data pelayanan klinis bayi baru lahir untuk FKTP berupa bagan alur menajemen bayi baru lahir yang terbagi menjadi bayi baru lahir normal dan bayi baru lahir dengan asfiksia. Asuhan bayi baru lahir dan tindakan penilainnya. Selain itu juga formulir panduan pemeriksaan fisik yang dilakukan pada bayi baru lahir, formulir bayi baru lahir dan penerbitan surat keterangan lahir.

Hasil keluaran formulir bayi baru lahir dan surat keterangan kelahiran yang diinginkan oleh user telah terpetakan (terlampir pada lampiran 1 dan 2). Formulir tersebut berisi data-data pelayanan secara lengkap dan terstruktur disertai otentifikasi legalitas terdiri dari pemberi layanan, penerima layanan, dan saksi.

\section{Tahap Perencanaan Aksi}

Peneliti dan responden (dokter dan bidan) bersama-sama memahami pokok masalah yang ada terkait pelaksanaan manajemen pelayanan neonatal, kemudian dilanjutkan dengan menyusun rencana tindakan yang tepat untuk menyelesaikan masalah yang ada berdasarkan algoritma MTBS. Pada tahap ini perancangan aplikasi mulai memasuki tahapan perancangan sistem dengan memasuki tahap model prototipe ke dua dan tiga yaitu mengembangkan prototipe dan evaluasi prototipe.

Pengembangan prototype dilakukan dengan mapping kebutuhan data terkait pelayanan klinis 
bayi baru lahir yang telah diperoleh pada tahap sebelumnya (tahap identifikasi kebutuhan), kemudian membuat mekanisme inferensi untuk mendeteksi kebutuhan pelayanan. Tahap ini dihasilkan Data Flow Diagram (DFD) sebagai berikut:



Gambar 5. 1 DFD Level 0 Prototype SPKK manajemen neonatal di FKTP

Diagram alir data adalah teknik grafik yang digunakan untuk menjelaskan aliran informasi dan transformasi data dari masukan hingga keluaran (Mulyanto, 2009). DFD level 0 atau biasa juga disebut diagram konteks merupakan gambaran bagaimana sistem berinteraksi dengan eksternal entity, dalam hal ini yaitu user yang terdiri dari bidan pelaksana kegiatan terkait pelayanan klinis bayi baru lahir di FKTP.

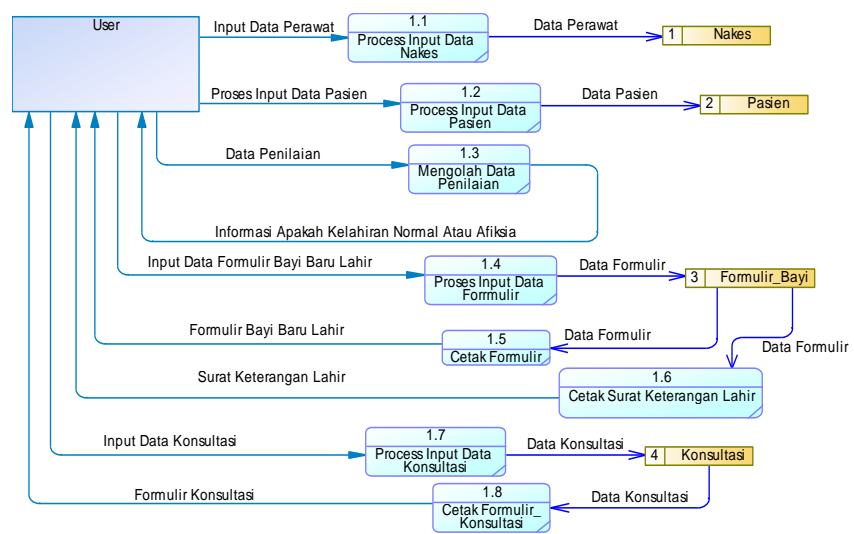

Gambar 5.2 DFD Level 1 Prototype SPKK manajemen neonatal di FKTP

DFD level 1 (gambar 5.2) menunjukkan menjabaran lebih rinci dari DFD level 0 terakit masukan-proses dan keluaran pada sistem pendukung kelengkapan data pelayanan klinis bayi baru lahir. DFD dalam bahasa Indonesia disebut sebagai DAD (Data Arus Data) memperlihatkan gambaran tentang masukan-proses-keluaran dari suatu sistem/perangkat lunak, kemudian ditransformasi oleh elemen-elemen pemprosesan dan objek-objek data mengalir kedalam perangkat lunak, kemudian ditransformasi oleh elemen-elemen pemprosesan, dan objek-objek data hasilnya akan mengalir keluar dari sistem atau perangkat lunak [5].

Gambar 5.3 menunjukkan desain Entity Relation Diagram (ERD) Prototype Pendukung Kelengkapan Data Pelayanan Klinis Bayi Baru Lahir di FKTP. ERD adalah suatu model jaringan kerja (network) yang menguraikan susunan data yang disimpan dari sistem secara abstrak [5]. Gambar ERD berikut menjelaskan hubungan antar data dalam basis data yang mempunyai hubungan antar relasi yaitu antara entitas nakes (tenaga kesehatan) dalam hal ini bidan atau dokter penanggungjawab pelaksana pelayanan dengan entitas pasien, pelayanan dan formulir bayi.

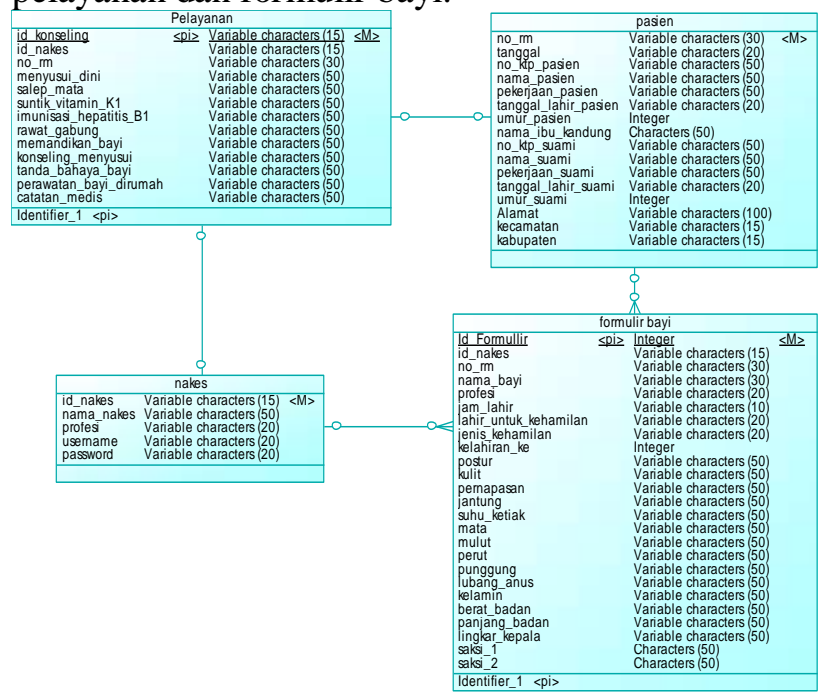

Gambar 5.3 ERD Prototype SPKK manajemen neonatal di FKTP

Tahap ketiga dari model prototipe adalah evaluasi prototype. Hasil dari pengembangan prototype berupa DFD dan ERD akan diimplementasikan dan dievaluasi apakah dapat diterima oleh user. User pada penelitian ini adalah responden yang akan menggunakan aplikasi hasil operasional dari prototype yang dikembangkan. Evaluasi dilakukan melalui kegiatan diskusi kembali dengan para responden yaitu bidan pelaksana pelayanan neonatal di FKTP. User mengevaluasi apakah sistem yang sudah jadi sudah sesuai dengan yang diharapkan. Jika sudah, maka langkah 
selanjutnya tahap pelaksanaan aksi berupa pengkodean sistem, namun jika belum maka mengulangi langkah 1 dan 2 .

\section{Tahap Pelaksanaan Aksi}

Tahap ini peneliti mengimplementasikan rencana tindakan ke perancangan antarmuka SPKK, database, mesin inferensi sesuai dengan kebutuhan sistem. Pada model prototipe masuk ke tahap empat dan lima. Tahap ke empat yaitu mengkodekan sistem, dan tahap ke lima adalah menguji sistem. Tahap mengkodekan sistem berupa prototyping yang sudah disepakati dilakukan koding dengan diterjemahkan ke dalam bahasa pemrograman. Kemudian memasuki tahap menguji sistem dengan makukan uji dari segi logik dan fungsionalitas program untuk meneliti dan meminimalisir terjadinya error. Hasil uji sistem menggunakan teknik black-box yang diperoleh hasil $100 \%$ berhasil. Hal tersebut nampak pada kesesuaian antara skenario uji dan hasil yang diharapkan sesuai, tersaji pada tabel berikut:

\section{Tabel 5.2 Pengujian Sistem}



\begin{tabular}{|c|c|c|c|c|}
\hline $\begin{array}{l}1 \\
0\end{array}$ & $\begin{array}{l}\text { Dapat } \\
\text { menampilkan } \\
\text { formulir } \\
\text { Konsultasi }\end{array}$ & $\begin{array}{l}\text { Menampilkan } \\
\text { fomulir } \\
\text { Konsultasi }\end{array}$ & $\begin{array}{l}\text { Data formulir } \\
\text { dapat di } \\
\text { tampilkan } \\
\text { berdasarkan } \\
\text { id } \\
\end{array}$ & Berhasil \\
\hline $\begin{array}{l}1 \\
1\end{array}$ & $\begin{array}{l}\text { Dapat } \\
\text { menampilkan } \\
\text { keterangan lahir }\end{array}$ & $\begin{array}{l}\text { Menampilkan } \\
\text { keterangan } \\
\text { lahir }\end{array}$ & $\begin{array}{l}\text { Data } \\
\text { keterangan } \\
\text { lahir dapat di } \\
\text { tampilkan } \\
\text { berdasarkan } \\
\text { id } \\
\end{array}$ & Berhasil \\
\hline $\begin{array}{l}1 \\
2\end{array}$ & $\begin{array}{l}\text { Dapat } \\
\text { menampilkan } \\
\text { data Klasifikas }\end{array}$ & $\begin{array}{l}\text { Menampilkan } \\
\text { data } \\
\text { Klasifikasi }\end{array}$ & $\begin{array}{l}\text { Data Nakes } \\
\text { dapat } \\
\text { ditampilkan }\end{array}$ & Berhasil \\
\hline $\begin{array}{l}1 \\
3\end{array}$ & $\begin{array}{l}\text { Dapat } \\
\text { melakukan edit } \\
\text { data Klasifikasi }\end{array}$ & $\begin{array}{l}\text { Mengubah } \\
\text { data bbu }\end{array}$ & $\begin{array}{l}\text { Data } \\
\text { Klasifikasi } \\
\text { berubah }\end{array}$ & Berhasil \\
\hline $\begin{array}{l}1 \\
4\end{array}$ & $\begin{array}{l}\text { Dapat } \\
\text { melakukan save } \\
\text { data Klasifikasi }\end{array}$ & $\begin{array}{l}\text { Meyimpan } \\
\text { data } \\
\text { Klasifikasi }\end{array}$ & $\begin{array}{l}\text { Data } \\
\text { Klasifikasi } \\
\text { dapat } \\
\text { disimpan }\end{array}$ & Berhasil \\
\hline $\begin{array}{l}1 \\
5\end{array}$ & $\begin{array}{l}\text { Dapat } \\
\text { melakukan } \\
\text { search data } \\
\text { Klasifikasi }\end{array}$ & $\begin{array}{l}\text { Mencari data } \\
\text { pasien untuk } \\
\text { Klasifikasi }\end{array}$ & $\begin{array}{l}\text { Data } \\
\text { Klasifikasi } \\
\text { dapat mencari } \\
\text { data } \\
\text { berdasarkan } \\
\text { nama pasien }\end{array}$ & Berhasil \\
\hline $\begin{array}{l}1 \\
6\end{array}$ & $\begin{array}{l}\text { Dapat } \\
\text { menampilkan } \\
\text { data Penilaian }\end{array}$ & $\begin{array}{l}\text { Menentukan } \\
\text { kondisi bayi }\end{array}$ & $\begin{array}{l}\text { Data } \\
\text { penilaian } \\
\text { dapat } \\
\text { menampilkan } \\
\text { hasil dari } \\
\text { pertanyaan } \\
\text { yang di jawab }\end{array}$ & Berhasil \\
\hline $\begin{array}{l}1 \\
7\end{array}$ & $\begin{array}{l}\text { Dapat } \\
\text { menampilkan } \\
\text { data Penilaian }\end{array}$ & $\begin{array}{l}\text { Menentukan } \\
\text { kondisi bayi }\end{array}$ & $\begin{array}{l}\text { Data } \\
\text { penilaian } \\
\text { dapat } \\
\text { menampilkan } \\
\text { hasil dari } \\
\text { pertanyaan } \\
\text { yang di jawab }\end{array}$ & Berhasil \\
\hline $\begin{array}{r}1 \\
-8\end{array}$ & $\begin{array}{l}\text { Dapat } \\
\text { menampilkan } \\
\text { data Konseling }\end{array}$ & $\begin{array}{l}\text { Menampilkan } \\
\text { data } \\
\text { Konseling }\end{array}$ & $\begin{array}{l}\text { Data } \\
\text { Konseling } \\
\text { dapat } \\
\text { ditampilkan } \\
\end{array}$ & Berhasil \\
\hline $\begin{array}{l}\mathbf{N} \\
\mathbf{0}\end{array}$ & Fungsionalitas & Skenario Uji & $\begin{array}{l}\text { Hasil yang } \\
\text { diharapkan }\end{array}$ & Kesimpulan \\
\hline $\begin{array}{l}91 \\
9\end{array}$ & $\begin{array}{l}\text { Dapat } \\
\text { melakukan } \\
\text { search data } \\
\text { Pasien }\end{array}$ & $\begin{array}{l}\text { Mencari data } \\
\text { Pasien untuk } \\
\text { Konseling }\end{array}$ & $\begin{array}{l}\text { Data } \\
\text { Klasifikasi } \\
\text { dapat mencari } \\
\text { data } \\
\text { berdasarkan } \\
\text { nama pasien }\end{array}$ & Berhasil \\
\hline $\begin{array}{l}2 \\
0\end{array}$ & $\begin{array}{l}\text { Dapat } \\
\text { melakukan } \\
\text { search data } \\
\text { Nakes }\end{array}$ & $\begin{array}{l}\text { Mencari data } \\
\text { Nakes untuk } \\
\text { Konseling }\end{array}$ & $\begin{array}{l}\text { Data } \\
\text { Klasifikasi } \\
\text { dapat mencari } \\
\text { data } \\
\text { berdasarkan } \\
\text { nama Nakes }\end{array}$ & Berhasil \\
\hline $\begin{array}{l}2 \\
1\end{array}$ & $\begin{array}{l}\text { Dapat } \\
\text { melakukan save } \\
\text { data Klasifikasi }\end{array}$ & $\begin{array}{l}\text { Meyimpan } \\
\text { data } \\
\text { Klasifikasi }\end{array}$ & $\begin{array}{l}\text { Data } \\
\text { Klasifikasi } \\
\text { dapat } \\
\text { disimpan }\end{array}$ & Berhasil \\
\hline $\begin{array}{l}2 \\
2\end{array}$ & $\begin{array}{l}\text { Dapat } \\
\text { melakukan } \\
\text { search data } \\
\text { Klasifikasi } \\
\end{array}$ & $\begin{array}{l}\text { Mencari data } \\
\text { pasien untuk } \\
\text { Klasifikasi }\end{array}$ & $\begin{array}{l}\text { Data } \\
\text { Klasifikasi } \\
\text { dapat mencari } \\
\text { data }\end{array}$ & Berhasil \\
\hline
\end{tabular}




\begin{tabular}{ll}
\hline $\begin{array}{l}\text { berdasarkan } \\
\text { nama pasien }\end{array}$ & an \\
\hline
\end{tabular}

\section{Tahap Evaluasi}

Tahap ini merupakan tahap akhir dari metode action research, dan memasuki tahap ke enam dan tujuh dari model prototipe. Tahap keenam dan ke tujuh merupakan tahap akhir yang terdiri dari evaluasi sistem dan menggunakan sistem. User mengevaluasi apakah SPKK yang sudah jadi telah sesuai dengan yang diharapkan. Evaluasi dilakukan dengan penggunaan tampilan aplikasi oleh user. Tampilan awal dimulai dengan halaman login.

1) Halaman Login

Alur program pada halaman login ditunjukan pada gambar berikut:

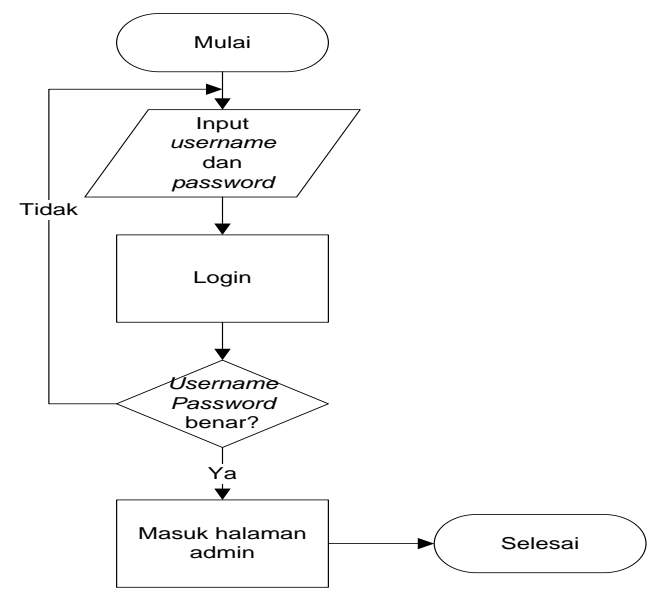

Gambar 5.4 Flowchart Program Form Login

Alur program dimulai dengan masuk ke form login menginputkan username dan password kemudian dengan klik tombol login. Jika username dan password benar maka masuk ke halaman beranda dan jika salah maka akan kembali ke halaman login.

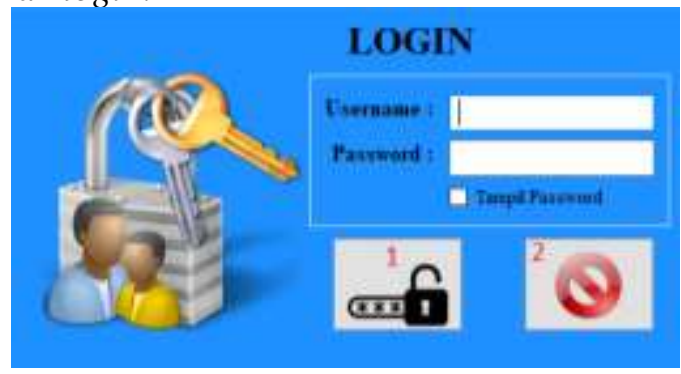

Gambar5.5 Tampilan login

Tampilan login berisi menu untuk

menentukan mau memakai hak akses dokter atau bidan. Sehingga menu yang di tampilkan berbeda beda, adapun notifikasi yang keluar terdiri dari angka 1 dan 2 sebagai berikut:

Angka 1 untuk memproses apakah username dan password sudah terdarftar apa tidak jadi akan muncul sebuah hak akses DOKTER atau BIDAN.

b. Angka 2 untuk membatalkan proses login.

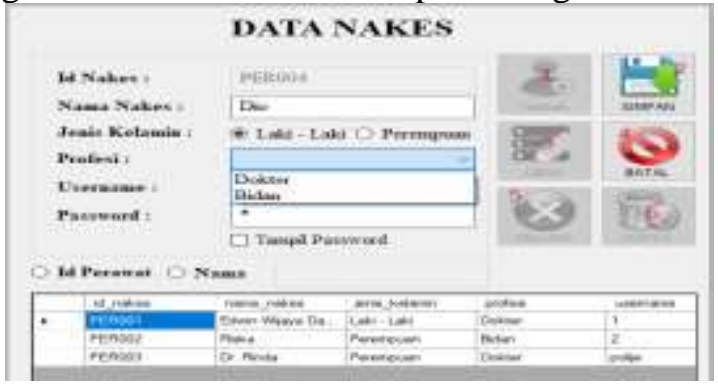

Gambar 5.6 Tampilan Data Nakes

Menu Data Nakes pada gambar 5.6 berfungsi untuk menambahkan / mendaftar data nakes yang baru, dan juga dapat digunakan untuk melihat data nakes yang sudah terdaftar. Hal ini sesuai dengan hasil identifikasi kebutuhan kepada user melalui kegiatan wawancara dan diskusi.

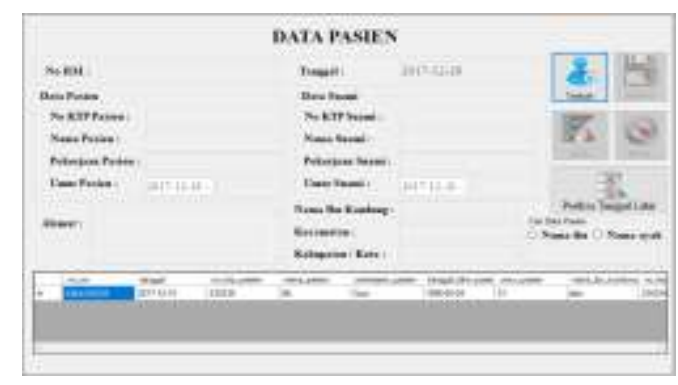

Gambar 5.7 Tampilan Data Pasien

Menu tampilan Data Pasien berfungsi untuk menambahkan atau mendaftar data pasien yang baru, dan juga dapat digunakan untuk melihat data pasien yang sudah terdaftar. Pada menu data pasien terdiri dari inputan data sosial pasien yang dibutuhkan untuk kelengkapan administratif.

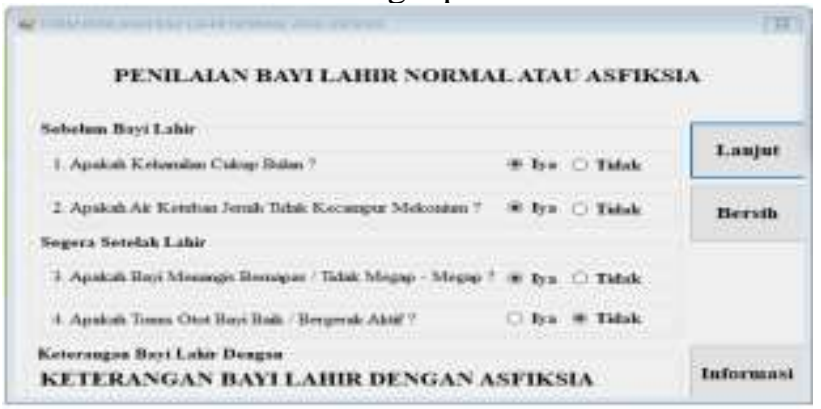

Gambar 5.8 Menu Penilaian 
Menu selanjutnya dari SPKK adalah berupa penilaian seperti yang tersaji pada gambar 5.8 di atas. Untuk kriteria penilaian sendiri ada 2 yaitu : normal dan asfiksia. Pada SPKK ini mengikuti alur algoritma MTBS sehingga setiap pemilihan kondisi sesuai hasil pemeriksaan klinis pada bayi baru lahir akan menuntun pada arahan asuhan tindakan klinis yang harus dilakukan oleh tenaga kesehatan. Gambar 5.9 berikut menampilkan tampilan arahan asuhan berdasarkan hasil penilaian klinis.

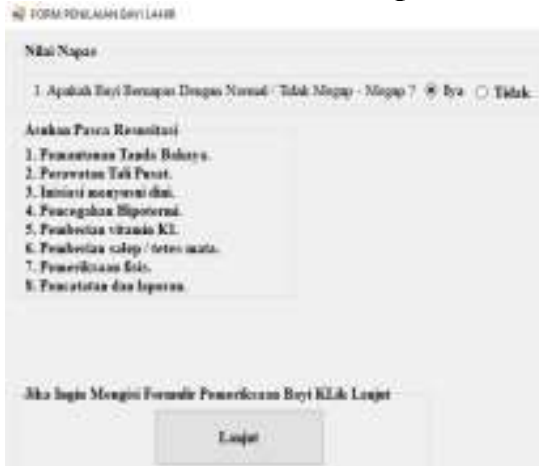

Gambar 5.9 Tampilan asuhan tindakan berdasar hasil penilaian klinis

SPKK manajemen neonatal yang dibangun ini juga dilengkapi dengan menu data bayi baru lahir dan konsultasi. Menu data bayi baru lahir dapat menghasilkan output berupa laporan kelahiran dan surat keterangan lahir, sedangkan menu konsultasi menghasilkan laporan pelayanan yang dilakukan.

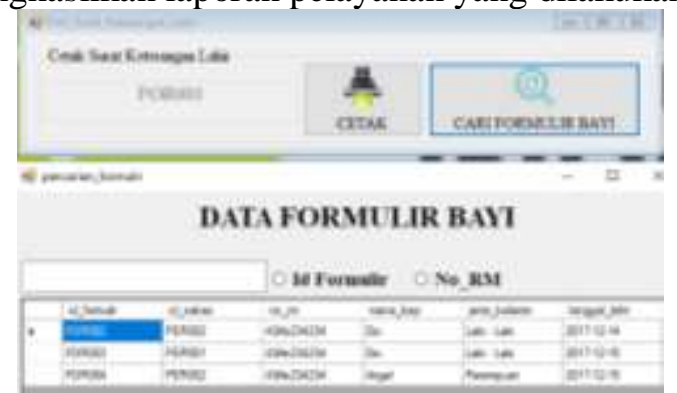

Gambar 5.10 Tampilan Data formulir bayi dan Menu cetak surat keterangan lahir

Data formulir bayi dan surat keterangan lahir diperlukan terkait kebutuhan kelengkapan data untuk informasi kelahiran. Adanya kejadian penculikan dan perdagangan bayi yang termasuk kriteria perdagangan orang (traficking in person) diharapkan dapat dihindari dengan adanya kelengkapan perekapan data pada pelayanan bayi baru lahir secara legal.



Gambar 5.10 Tampilan Data formulir konsultasi dan Menu cetak

Gambar 5.10 menampilkan interface dari menu SPKK manajemen neonatal berupa menu cetak formulir konsultasi dan dan menu cetak formulir pemeriksaan. Hal tersebut diperlukan bagi pasien, keluarga pasien, pihak ke tiga atau pemberi jaminan pembiyaan dan untuk tenaga kesehatan sendiri terkait pelaporan dan perekapan data manual yang diperlukan.

Tahap ke tujuh dari model prototipe adalah menggunakan sistem. Pada tahap ini perangkat lunak SPKK manajemen neonatal berbasis algoritma yang telah diuji dan diterima user siap untuk digunakan dalam mendukung pelayanan klinis.

\section{KESIMPULAN}

Sistem pendukung keputusan klinis manajemen neonatal yang dihasilkan pada penelitian ini telah sesuai dengan kebutuhan user dalam melakukan pelayanan neonatal berbasis algoritma MTBS di fasilitas pelayanan primer. Hasil pengujian sistem menggunakan teknik black-box sesuai dengan persyaratan dan diperoleh hasil keseluruhan yang valid.

\section{UCAPAN TERIMA KASIH}

Ucapan terima kasih penulis tujukan kepada program pendanaan penelitian DRPM Kemenristekdikti nomor: 482 / PL17.4 / PL / 2018 yang telah mendanai penelitian ini.

\section{DAFTAR PUSTAKa}

[1] Depkes RI. 2014. PERMENKES Nomor 53 Tahun 2014 Tentang Pelayanan Kesehatan Neonatal Esensial. Jakarta

[2]World Health Organization. 2015. Neonatal Mortality. WHO. Genewa. Diunduh: www.who.int/gho/childhealth/mortality/neonatal/en/ 
[3] Badan Pusat Statistik. 2016. Angka Kematian Bayi. BPS Jakarta.

[4] WHO. 2016. World Health Statistics 2016 : Monitoring Health For The SDGs. Diaksesdari http://apps.who.int/iris/bitstream/10665/206498/1/9 789241565264_eng.pdf

[5] Karimah, Rinda dan Wicaksono Andri. 2018. Prototype Sistem Informasi Pelayanan Bayi Baru Lahir pada Fasilitas Kesehatan Primer. Jurnal Khazanah Informatika Vol. 4 No. 1 Juni 2018

[6] Blank A, Prytherch H, Kaltschmidt J, et al. Quality of Prenatal and Maternal Care: Bridging The KnowDo Gap. BMC Medical Informatics and Decision Making. Available from: http://www.pubmedcentral.nih.gov/articlerender.fc gi artid $=3637082 \&$ tool $=$ pmcentrez $\&$ rendertype $=a b$ stract

[7] KEMENKES RI, 2016. Buku Kesehatan Ibu dan Anak. Kementrian Kesehatan RI dan JICA. Jakarta.

[8] KEMENKES RI, 2015. Buku Bagan Manajemen Terpadu Balita Sakit (MTBS), Jakarta.

[9] Abdullah, A. L., Albeladi, K. S., \& AlCattan, R. F. 2014. Clinical decision support system in healthcare industry success and risk factors. International Journal of Computer Trends and Technology, 11(4), 188-192.

[10] Kumar, A. (2015). Stakeholder's Perspective of Clinical Decision Support System. Open
Journal of Business and Management, 4(01), 45.

[11] Kusumadewi, S, dan Hartati, S. 2007. "Utilizing Fuzzy Multi-Attributr Decision Making for Group Clinical Decision Making Model”, Proccedings of International Conference on Soft Computing, Intelligent System \& Information Technology (ICSIIT 2007), pp. 18-24, UK Petra, Surabaya.

[12] Amalia H \& Evicienna. 2017. Aplikasi Sistem Penunjang Keputusan Untuk Prediksi Ibu Melahirkan. Jurnal Ilmu Pengetahuan Dan Teknologi Komputer VOL. 3. NO. 1 Agustus 2017 E-ISSN: 2527-4864.

[13] Meilantika Dian. 2017. Rancang Bangun Sistem Informasi Administrasi Menggunakan Metode Throwaway Prototyping Development Pada Sultan-Sport. JUTIM Vol 2 No 2. Desember 2017. STMIK Musirawas.

[14] Djauhari T, Assegaff S. 2016. Perancangan Sistem Informasi Layanan Persidangan Pada Pengadilan Negeri Sengeti. Jurnal Manajemen Sistem Informasi Vol 1 No. 1, September 2016.

[15] Listiarsasih dkk. 2016. Efektifitas Media Video Penggunaan Spill Kit Terhadap Kemampuan Petugas di RS PKU Muhammadiyah Yogyakarta Unit II. Jurnal Asosiasi Dosen Muhammadiyah Magister Administrasi Rumah Sakit Vol 2 No 2 Juli 2016. 